\title{
Climate change and economic growth: Some critical reflections
}

\author{
Alfred Greiner
}




\title{
Climate change and economic growth: Some critical reflections
}

\author{
Alfred Greiner*
}

\begin{abstract}
Empirical studies analyzing the effect of climate change on output growth sometimes neglect economic variables. This yields a biased picture of the growth process and does not represent a good approximation of the true data generating process. Thus, the question arises how valid the results are so that analyses investigating the robustness of the outcome with respect to integrating economic variables should be carried out.
\end{abstract}

The question which factors cause economic growth has been as old as economics as a scientific discipline (for a short survey see e.g. Greiner, 1996, ch. 2.1). Using modern econometric methods to detect the forces of economic growth has started in the 1950's with a seminal paper written by Solow (1957) who implicitly builds on Tinbergen (1942) who was the first to integrate a time index in the aggregate production function. Solow's great merit was to show how a measure of the technical progress can be estimated from real world data accounting for that part of GDP growth that is not explained by increases in capital and labor input.

In the following decades numerous empirical studies have been undertaken aiming to enhance our understanding of the process of economic growth. But researchers often limit their analyses to only a limited number of explanatory variables so that the question arises how reliable and valid their results are. As regards that problem Leamer (1985) states

${ }^{*}$ Department of Business Administration and Economics, Bielefeld University, P.O. Box 100131, 33501 Bielefeld, Germany, e-mail: agreiner@uni-bielefeld.de 
that "We must insist that all empirical studies offer convincing evidence of inferential sturdiness. We need to be shown that minor changes in the list of variables do not alter fundamentally the conclusions, nor does a slight reweighting of observations, nor correction for dependence among observations, etcetera, etcetera." (Leamer, 1985, p. 308). Thus, Levine and Renelt (1992) perform an extreme-bounds analysis, based on Leamer (1983), where they investigate which variables always exert a statistically significant effect, independent of which other variables are included in the regression, in explaining economic growth (for details as to that analysis, see Levine and Renelt, p. 944). They find that only few variables are robust as defined by them, such as the investment share, trade and the initial level of GDP. Sala-i-Martin (1997) argues that the extreme-bounds analysis is too restrictive since it allows only a zero-one labeling, i.e. a variable is either robust or it is not. Rather, he suggests to call a variable robust if $95 \%$ of the density of an estimated coefficient lie to the right or to the left of zero. Proceeding like that he finds additional variables to be robust like political variables, for example. Bruns and Ioannidis (2020) analyze whether the forces of economic growth change over time or remain the same independent of which time period is considered. They find that inferences on growth determinants are not stable across time periods. Nevertheless, variables such as the investment share and trade are statistically significant in the more recent growth period until 2010, too.

The accumulation of greenhouse gases like carbon dioxide and methane in the atmosphere will affect global climate and changes in the climatic conditions are likely to influence the economic system of societies. For example, more extreme weather events cause economic damages and require resources that cannot be used for consumption and/or for investment. Hence, it can be expected that changes of climatic conditions may have effects on the growth rates of aggregate GDP and there exist empirical studies dealing with that problem.

Two examples dealing with this type of research are Burke et al. (2015) and Kotz et al. (2021) who perform panel studies where the growth rate represents the dependent variable that is regressed on climatic variables such as the temperature, precipitation, temperature variability and on changes of those variables. We do not go further into the details because our contribution is not to be seen as a critique of those studies, but, the latter rather serve as a peg for our reflections. Those studies, however, focus on only one potentially relevant bundle of physical factors while neglecting economic variables 
that have turned out to be important in explaining economic growth, thus, giving rise to the problem of omitted variables. From an econometric point of view this can lead to inconsistent estimations of the coefficients when the explanatory variables are correlated with the residuals. Even if that problem can be overcome technically in fixed effects panel regression models by introducing dummies as noted and done in Kotz et al. (2021, p. 326), the problem of missing economic variables remains such that the estimated model may not be a good proxy for the true data generating process and may not yield the true effect of climate variables. In the two papers mentioned in this paragraph, this is reflected in the relatively low value for the coefficient of determination, where the adjusted $R^{2}$ does not exceed 25 percent in Kotz et al. and where the $R^{2}$ in Burke et al. falls short of 30 percent, except for their model 5, where it amounts to 37 percent.

The philosopher Kant has stated that theory without empirics is empty and empirics without theory is blind, "Gedanken ohne Inhalt sind leer, Anschauungen ohne Begriffe sind blind." (Kant, 1787, p. 91). In market economies, the growth of aggregate GDP is the result of decisions of individuals and of firms that act intentionally to achieve economic goals. Hence, econometric models explaining growth should be based on sound economic theory and contain economic explanatory variables. Neglecting the latter and positing that growth solely depends on climatic factors can lack important aspects and may yield a biased picture of the real world. Thus, the outcomes of such models should be considered with care. That holds in particular when the emphasis is put on the exact numerical values of the estimated coefficients rather than on their qualitative contents, e.g. whether an explanatory variable exerts a positive or negative effect on the dependent variable. Focusing on the exact numbers would imply a perception of knowledge and precision that the models cannot deliver and may generate inadequate policy measures.

\section{References}

Bruns, Stephan B., Ioannidis, John P.A. (2020) "Determinants of economic growth: Different time different answer." Journal of Macroeconomics 63103185 , https://doi.org/10.1016/j.jmacro.2019.103185

Burke, Marshall, Hsiang, Solomon M., Miguel Edward (2015) "Global non-linear ef- 
fect of temperature on economic production." Nature Letter, Vol. 527: 235-250, https://doi.org/10.1038/nature15725

Greiner, Alfred (1996) Fiscal Policy and Economic Growth. Ashgate Publishing Company, Aldershot, England

Kant, Immanuel (1787) Kritik der reinen Vernunft. Herausgegeben von Benno Erdmann, Sechste revidierte Auflage, Berlin und Leipzig 1923, Walter de Gruyter.

Kotz, Maximilian, Wenz, Leonie, Stechmesser, Annika, Kalkuhl, Matthias, Levermann, Anders (2021) "Day-to day temperature variability reduces economic growth." Nature Climate Change, Vol. 11: 319-325, https://doi.org/10.1038/s41558-020-00985-5

Leamer, Edward E. (1983) "Let's Take the Con Out of Econometrics." American Economic Review, Vol. 73, no. 1: 31-43.

Leamer, Edward E. (1985) "Sensitivity Analyses Would Help." American Economic Review, Vol. 75, no. 3: 308-313.

Levine, R., Renelt, D. (1992) "A sensitivity analysis of cross-country growth regressions." American Economic Review, Vol. 82, no. 4: 942-963.

Sala-i-Martin, Xavier S. (1997) "I just ran two million regressions." American Economic Review, Papers and Proceedings, Vol. 87, no. 2: 178-183.

Solow, Robert M. (1957) "Technical change and the aggregate production function." The Review of Economics and Statistics, Vol. 39, no. 3: 312-320.

Tinbergen, Jan (1942) "Zur Theorie der langfristigen Wirtschaftsentwicklung." Weltwirtschaftliches Archiv, Vol. 55: 511-549. 